\title{
Characterization and In Vitro Assessment Of Three- Dimensional Extrusion Mg-Sr Codoped SiO2- Complexed Porous Micro-Hydroxyapatite Whisker Scaffolds For Bone Tissue Engineering
}

Chengyong Li ( $\sim$ lichengyonglcy666@163.com )

First Affiliated Hospital of Kunming Medical University

Tingting Yan

Kunming University of Science and Technology

Zhenkai Lou

First Affiliated Hospital of Kunming Medical University

Zhimin Jiang

Kuning University of Science and Technology

Zhi Shi

First Affiliated Hospital of Kunming Medical University

Qinghua Chen

Kunming University of Science and Technology

\section{Zhiqiang Gong}

First Affiliated Hospital of Kunming Medical University

Bing Wang

First Affiliated Hospital of Kunming Medical University

\section{Research Article}

Keywords: micron hydroxyapatite whiskers, extrusion molding, porous ceramic scaffold, bone tissue engineering,

Posted Date: June 15th, 2021

DOl: https://doi.org/10.21203/rs.3.rs-587482/v1

License: (9) (1) This work is licensed under a Creative Commons Attribution 4.0 International License. Read Full License 


\section{Abstract}

Background Orthopedics has made great progress with the development of medical treatment; however, large bone defects are still great challenges for orthopedic surgeons. A good bone substitute that can be obtained through bone tissue engineering may be an effective treatment method. Artificial hydroxyapatite is the main inorganic component of bones, but its applications are limited due to its fragility and lack of bone-active elements. Therefore, it is necessary to reduce its fragility and improve its biological activity.

Methods In this study, we developed micro-hydroxyapatite whiskers (mHAws), which were doped with the essential trace active elements $\mathrm{Mg}^{2+}$ and $\mathrm{Sr}^{2+}$ through a low-temperature sintering technique, used silica complexes to improve the mechanical properties, and then manufactured the bionic porous scaffolds by extrusion molding and freeze-drying.

Results Four types of scaffolds were obtained: $\mathrm{mHAw}_{-} \mathrm{SiO}_{2}, \mathrm{Mg}$-doped $\mathrm{mHAw}_{-} \mathrm{SiO}_{2}$, Sr-doped $\mathrm{mHAw}-\mathrm{SiO}_{2}$ and $\mathrm{Mg}$-Sr-codoped $\mathrm{mHAw}_{-} \mathrm{SiO}_{2}$. These composite porous scaffolds have been suggested to have a sufficiently porous morphology with appropriate mechanical strength, are noncytotoxic, are able to support cell proliferation and spreading, and, more importantly, can promote the osteogenic differentiation of rBMSCs.

Conclusion Therefore, these doped scaffolds not only have physical and chemical properties suitable for bone tissue engineering, but also have higher osteogenic bioactivity, and can be possibly serve as potential bone repair material.

\section{Introduction}

Bones are the main supports and structures for movement in the human body, which can provide protective spaces for the brain, heart, lungs, liver, and other organs. Bones also possess a robust regenerative capacity and can regenerate completely under the appropriate conditions after they are broken or slightly injured. Bone healing consists of three continuous and partially overlapping processes[1]. In the first stage, immunoregulation, stem cell recruitment and chondrogenesis occur. In the second stage, cartilage is absorbed, and new bone is formed under the combined action of osteoclasts and osteoblasts. In the third stage, the newly formed remodeled bone returns to normal, and the repair is complete. However, when a bone defect is too large to heal itself, it is called a large-size or critical-size bone defect, and it cannot spontaneously complete the repair process.

Large-size bone defects are always caused by severe trauma, tumor removal, infection, or congenital malformation, and reconstruction of these defect sites is a major challenge for orthopedic surgeons and patients [2, 3]. Currently, the main treatment measures for these large bone defects include autogenous bone grafts, allografts, and artificial bone substitutes[3-5]. However, the above treatment methods have specific deficiencies during the treatment process. Autografts, as the gold standard, have complications including an increased surgical site, limited bone mass, bleeding, and additional pain. Allografts frequently pose risks, including immunological rejection and pathophoresis from the donor. Hopefully, 
bone tissue engineering (BTE) can provide more choices for patients with bone defects, although there is still much to be done to approach or achieve the therapeutic effects of autologous bone. Notably, the application of single materials will always present problems such as poor mechanical properties, poor osteogenic properties, tumorigenicity, and mismatch between the degradation rate and the rate of new bone formation[5, 6].

Over the past few years, BTE has been used to promote bone regeneration, as substantial efforts and confidence has been placed in the scientific research. With the development of new technologies, different types of scaffolds have been developed and applied in bone repair, but only a few scaffolds have shown satisfactory results $[5,7,8]$. Bones are made of an outer layer of cortical bone and an inner layer of cancellous bone that is characterized by a porous structure. Load-bearing bones are mostly tubular. The major organic component of natural bone is type I collagen (COL1) and the major inorganic component is hydroxyapatite $\left(\mathrm{HA} ; \mathrm{Ca}_{10}\left(\mathrm{PO}_{4}\right)_{6}(\mathrm{OH})_{2}\right)[9]$, which also contains necessary elements, such as $\mathrm{Mg}^{2+}, \mathrm{Si}^{4+}$, and $\mathrm{Sr}^{2+}$, and other metal ions $[5,10-13]$.

As the main inorganic component of natural bone, hydroxyapatite can be divided into macroscopic, micron, and nanoscale sizes. HA has excellent biocompatibility, good cell adhesion and good osteoconductivity $[9,14-16]$. Research in recent years has confirmed that, compared with scaffolds based on HA particles, the use of scaffolds based on micron-sized HA whiskers (mHAws) during bone repair have a better hierarchical porous structure and enhanced mechanical properties as well as improved biological activity and biological responses[18-20]. The trace elements $\mathrm{Mg}^{2+}, \mathrm{Si}^{4+}$ and $\mathrm{Sr}^{2+}$ in bone also have important osteogenic and vascular functions. Mg has good osteoconductivity and osteoinductivity, promotes vasodilation, sprawling and new blood vessel formation, increases blood perfusion, and has good tissue affinity. It participates in early osteogenic differentiation, midterm new bone formation, and late bone remodeling[17-19]. Mg also has good biological safety in tissues and the blood and certain antibacterial properties (including resistance to methicillin-resistant Staphylococcus aureus)[20, 21]. However, its rapid degradation rate limits its applications in orthopedics[22]. Si is nontoxic or has only very low toxicity and shows good biocompatibility, degradability and biological excretion[23]. $\mathrm{Si}^{4+}$ can recruit bone marrow mesenchymal stem cells (BMSCs) and promote their osteogenic differentiation in the early stage, improve the adhesion and proliferation of osteoblasts, and promote the formation and structural stabilization of $\mathrm{COL} 1 . \mathrm{Si}^{4+}$ can also promote the precipitation and mineralization of the bone matrix in the midterm phase of bone repair. Moreover, angiopoietin-2 is upregulated through the cell signaling pathway to regulate blood vessel formation[5, 24-26]. Sr has outstanding antiosteoporosis performance through the inhibition of the differentiation and activity of osteoclasts and has certain osteogenic and strong angiogenic functions, as well as antibacterial properties[13, 27-31]. In addition, its bone repair effects are better when multiple ions cooperate together[9, 12, 30, 32]. An ideal bone repair material should be biocompatible, biodegradable, and nontoxic, have suitable physical properties and show good osteogenic and angiogenic abilities[4, 9, 32]. 
To avoid the high cost and technical difficulties of cell and growth factor application, pure biomaterials are feasible in terms of their availability, production, and approval. Inspired by the composition and porous structure of natural bone and the bone-forming functions of mHAws, magnesium, strontium and silica mentioned above, we investigated a facile strategy to fabricate a new bionic porous scaffold to facilitate bone defect site repair. Magnesium and strontium were sintered at low temperature and doped into mHAws as a slurry, and a silica complex was used to enhance the strength and toughness. Then, the lotus root-shaped scaffold was created by extrusion molding technology and freeze-drying.

\section{Results}

\subsection{Fabrication and characterization of the scaffolds}

Pure mHAw, Mg-doped mHAw, Sr-doped mHAw and Mg-Sr codoped mHAw were successfully synthesized. Scanning electron microscopy (SEM) observations and analysis showed that the length of the prefabricated mHAws ranged from a few microns to tens of microns, while the diameter of the mHAws were several microns (Figure 1A). The SHA, SMHA, SSHA and SMSHA scaffolds were prepared according to the mentioned method, as shown in Figure 7. Briefly, through low-temperature sintering, the doped mHAws were extruded into porous ceramics, complexed with silica to enhance their mechanical strength, and cut to the required size.

\subsection{Hydrophilicity properties}

As shown in Figure 1B-F, the WCAs of the SHA, SMHA, SSHA and SMSHA scaffolds were $5^{\circ}, 8^{\circ}, 6^{\circ}$ and $6^{\circ}$ after measurement. The smaller the WCA, the better the hydrophilicity. The WCAs of the four scaffolds all reflect good hydrophilicity. SHA had the smallest WCA, SMHA had the largest WCA, and SSHA and SMSHA had the same WCA, indicating that the hydrophilicity of the scaffolds will be affected after doping with different ions. These biomaterials have good hydrophilicity, which is conducive to the attachment and growth of cells[33,34]. As SMHA has the largest WCA, SHA has the smallest WCA, and SSHA and SMSHA (both doped with Sr) have smaller WCAs than SMHA, this result indicates that Sr is more hydrophilic than $\mathrm{Mg}$.

\subsection{Pore sizes of the scaffold}

Since a significant feature of natural bone is its porous structure, the design of the porous structure in the ceramic bone scaffolds can provide favorable conditions for bone regeneration. The average pore sizes of SHA, SMHA, SSHA and SMSHA were $267.20 \pm 10.66 \mu \mathrm{m}, 247.40 \pm 23.66 \mu \mathrm{m}, 286.20 \pm 19.04 \mu \mathrm{m}$ and $269.40 \pm 33.00 \mu \mathrm{m}$, respectively (Figure 1G). Thus, the pore sizes of the four scaffolds are similar.

\subsection{Mechanical properties}


Compared with natural bone, most of the scaffolds that are developed for bone regeneration have insufficient mechanical properties. Therefore, it is necessary to develop a preparation process to improve the mechanical properties of scaffolds, and material methods and structural improvements have been used to achieve this goal. To reduce the risks of the high brittleness and fragility associated with hydroxyapatite, the prepared pure mHA scaffold, Mg-doped mHAw scaffold, Sr-doped mHAw scaffold and $\mathrm{Mg}$-Sr codoped mHAw scaffold were immersed in silica gel, and the mechanical properties of the scaffolds were found to be enhanced by $\mathrm{SiO}_{2}$ complexation. The Young's moduli of SHA, SMHA, SSHA and SMSHA were $122.43 \pm 28.79 \mathrm{MPa}, 164.56 \pm 32.99 \mathrm{MPa}, 188.44 \pm 47.89 \mathrm{MPa}$ and $163.28 \pm 50.55$ $\mathrm{MPa}$, respectively, as shown in Figure $1 \mathrm{H}$.

When developing a new bone tissue engineering material, in addition to other performance requirements for specific applications, the goal should be to prepare strong and stiff materials. HA is a weak bioceramic, so it cannot be used alone as the main load-bearing bone substitute in the human body. A high compressive strength can effectively support the surrounding tissues to prevent collapse[35] and the appropriate compressive strength can be adapted to the strength of natural bone. The compressive strengths of SHA, SMHA, SSHA and SMSHA were 1.72 $\pm 0.29 \mathrm{MPa}, 2.47 \pm 0.25 \mathrm{MPa}, 1.87 \pm 0.52 \mathrm{MPa}$ and $2.04 \pm 0.35 \mathrm{MPa}$, respectively (Figure 1I), and both SMHA and SMSHA were in the range of cancellous[36].

\subsection{SEM observations}

Promising scaffolds should have a suitable microscopic morphology to allow sufficient cell contact for the stimulation of cell responses. SEM confirmed that the four scaffolds (SHA, SMHA, SSHA and SMSHA) have a rough surface morphology, which meets the microscopic morphology required for osteogenic differentiation and the growth of BMSCs. We defined the surface of the scaffold with macropores as the macroporous surface of the scaffold (Figure 2A1-A2, B1-B2, C1-C2, and D1-D2) and the surface without macropores as the microporous surface of the scaffold (Figure 2A3-A4, B3-B4, C3-C4, and D3-D4). The macroporous surface has lotus root-like

pores, which facilitates blood penetration, blood vessel formation and the other functions mentioned above. More importantly, it also provides a bionic microenvironment for the stimulation of BMSC bioactivity. Moreover, both the macroporous surface and the microporous surface are rough, which is conducive to the attachment of cells.

\subsection{Element distribution and content of the scaffolds}

Except for silicon and oxygen, the EDS element mapping showed that the

distribution density of each element on the macroporous surface and the microporous surface was similar for each scaffold. Analysis showed that the main elements of SHA (Ca, P, O, and Si) (Figure S1 in 
the Supporting Information), SMHA (Ca, P, O, Si, and Mg) (Figure S2), SSHA (Ca, P, O, Si, and Sr) (Figure $\mathrm{S} 3$ ), and SMSHA (Ca, P, O, Si, Mg and $\mathrm{Sr}$ ) (macroporous surface shown in Figure 3B1-H1, microporous surface shown in Figure 3B2-H2) were uniformly distributed on the corresponding scaffold. It has therefore been indicated that this doping method is effective and feasible.

Elemental content analysis showed that four main peaks of $\mathrm{Ca}, \mathrm{P}, \mathrm{O}$ and $\mathrm{Si}$ can be detected for the four types of scaffolds, whether it is a macroporous surface (Figure 4A1-D1) or microporous surface (Figure 4A2-D2). Of the four scaffolds, Mg and Sr had different elements, SMHA had Mg peaks, SSHA had Sr peaks, and SMSHA had both Mg peaks and Sr peaks compared with SHA (Figure 4A1-A2). However, the elemental contents of the macroporous surfaces and the microporous surfaces were slightly different, and the SMHA scaffold doped with Mg showed a lower content of Mg than the Sr content of SSHA-doped Sr scaffold, which is related to the difficulty in replacing $\mathrm{Ca}^{2+}$ in $\mathrm{mHAws}$ with $\mathrm{Mg}^{2+}$ during the sintering process.

\subsection{In vitro cell studies}

\subsubsection{Cell viability and proliferation}

Cell live/dead staining confirmed that these scaffolds are beneficial to cell viability and growth. Living cells were stained green by calcein-AM, and dead cells were stained red by EthD-1, as observed by upright fluorescence microscopy. Most of the cells on the scaffolds were green living cells, and the red-stained dead cells were

almost invisible (Figure 5A-D). The CCK-8 assay is a typical way to test the proliferation of cells. CCK-8 solution reacts with dehydrogenase in the mitochondria of living cells to produce yellow formazan, and the amount of formazan produced is proportional to the number of living cells. A microplate reader was used to measure the optical density (OD) values to evaluate the number of living cells, which indirectly reflects the cytotoxicity of the scaffolds. The rBMSCs cultured on the four scaffolds had good viability, as shown in the experimental results in Figure 5E. The results of the live/dead staining and CCK-8 assays both confirmed that these four scaffolds have good biocompatibility and that their biosafety is favorable for the proliferation and spread of rBMSCs.

\subsubsection{The surface area and morphological shape of the rBMSCs}

After culturing for 3 and 7 days, observation of the morphological shape of the rBMSCs with an upright fluorescence microscope verified that the cells cocultured with the scaffolds may be a simple way to assess the area of cell spreading organization and cytoskeletal structure[37-39]. The shapes of the rBMSCs cocultured with the four types of scaffolds all showed different spreading organization areas (Figure 5F-J). The analysis showed that SMHA and SMSHA were more conducive to an increase in cell spreading organization, which may be related to doping with $\mathrm{Mg}$. 
Bone regeneration in the defect site requires the proliferation and differentiation of the surrounding BMSCs to spread and cross, and cell spreading is driven by filopodia, pseudopods and the cytoskeleton in a suitable physical and chemical environment. The morphological shape and filopodia and pseudopods were observed on rBMSCs cocultured with the four scaffolds and the rBMSCs cultivated with SMHA or SMSHA had a polygonal osteoblast-like shape and the largest number of filopodia and pseudopods (Figure 6A1-D2).

\subsubsection{The scaffolds induce the expression of genes related to bone formation in rBMSCs}

Next, the osteogenic abilities of these scaffolds was further verified. After 7 and 14 days of culture on the scaffolds, the expression levels of rBMSC bone-specific genes, including COL1 (main organic component of bone extracellular matrix), BMP2 (a factor that strongly promotes bone regeneration), Runx2 (osteoblastic transcript factor guide BMSCs to differentiate into osteoblasts) and ALP (biochemical marker of early osteogenesis) were determined along with the angiogenic gene VEGF

(growth factor to enhance vascularization for tissue repair) and housekeeping gene GAPDH (constantly expressed gene) were analyzed and evaluated by RT-qPCR (the primer sequences are shown in Table 1). Compared with the SHA scaffold, the rBMSCs cultured on the SMHA, SSHA and SMSHA scaffolds showed higher expression of COL1, BMP2, Runx2, ALP and VEGF on the $7^{\text {th }}$ and $14^{\text {th }}$ days, and the SMSHA scaffold displayed the highest expression (Figure 6E-J). The gene expression profiles of COL1, ALP, Runx2 and VEGF indicated good osteoblast proliferation and maturation.

Table 1. Sequences of the primers for RT-qPCR

\begin{tabular}{|lll|}
\hline Gene & Forward $\left(5^{\prime}\right.$ - $\left.^{\prime}\right)$ & Reverse $\left(3^{\prime}{ }^{\prime}{ }^{\prime}\right)$ \\
\hline COL1 & AAGAAGACATCCCTGAAG & AGATACAGATCAAGCATACA \\
\hline BMP2 & CATCACGAAGAAGCCATC & TCATCAGTAGGGACAGAAC \\
\hline Runx2 & AATGCCTCTGCTGTTATG & TTGTGAAGACCGTTATGG \\
\hline ALP & TGATGCTCAGGACAGGAT & GGACCATAAGCGAGTTTCT \\
\hline VEGF & CAGCATAGCAGATGTGAATG & TTCTCCGCTCTGAACAAG \\
\hline GAPDH & CCTGCACCACCAACTGCTTA & GGCCATCCACAGTCTTCTGAG \\
\hline
\end{tabular}

\section{Discussion}

Composite bone repair materials based on hydroxyapatite have been a mainstream research topic in recent years, but their applications are limited due to the inherent defects of hydroxyapatite. In contrast, mHAws may have better biological activity, which can be increased to generate a biological scaffold with 
a porous structure[9]. Our scaffolds have excellent hydrophilicity, and studies have revealed that the hydrophilic surface of biological materials can regulate the adsorption of fibronectin and fibrinogen and that these materials have a greater potential to promote the differentiation of macrophages into the antiinflammatory phenotype[ 40,41$]$. Therefore, when designing advanced implant materials with good antiinflammatory and osteogenesis properties, the surface design should consider the hydrophilicity. Notably, $\mathrm{Mg}^{2+}$ and the hydrophilic surface of a material have some of the same cell signaling pathways ( $\mathrm{PI} 3 \mathrm{~K}$ and NF-KB) in terms of exerting anti-inflammatory effects and assisting in osteogenesis[41-43].

The outer layer of natural bone is dense cortical bone with fewer pores, the inner layer is spongy cancellous bone with more pores, and natural bone structure bionic materials have better application advantages in BTE $[44,45]$. The pore sizes of the scaffold must match the requirements of bone regeneration to facilitate the migration, proliferation and osteogenic differentiation of BMSCs and provide space for the deposition of calcium and phosphorus while promoting the formation and growth of blood vessels to provide nutrients and transportation of metabolic waste[4, 46-48]. The ideal pore size range for new bone regeneration is $150-350 \mu \mathrm{m}[4]$. mHAw-based scaffolds show roughness and have micropores, and the porous scaffold extruded by this die has more abundant pores with a suitable pore diameter, which is beneficial to the additive manufacturing of BTE. Therefore, the pore diameters and rough surface morphology of mHAw-based scaffolds may meet our needs.

The excellent mechanical properties of porous scaffolds can provide sufficient physical support and biochemical stimulation to facilitate bone formation[49]. The elastic modulus is an important index to measure the stiffness of a material, and the Young's modulus is the most important and characteristic mechanical property of elastic materials. In terms of the mechanical properties of natural bone, the compressive strength of cancellous bone is $2-12 \mathrm{MPa}$, and the compressive strength of cortical bone is $100-230 \mathrm{MPa}[36]$. The modulus of elasticity of cortical bone is $5-27 \mathrm{GPa}$ and that of cancellous bone is 0.76-20 GPa[50, 51]. In this study, silica was complexed with the scaffolds to enhance their mechanical properties. The elastic moduli of the four scaffolds were relatively close to that of cancellous bone, and the strength of the scaffolds could support local soft tissues. Thus, silica is suitable as a bone defect filler.

HA chemically modified by ionic substitution has been demonstrated to be more advantageous than HA alone in accelerating bone regeneration and promoting the reabsorption of cell-mediated ceramic scaffolds[12, 52, 53]. HA coatings containing biologically the active elements $\mathrm{Mg}$, $\mathrm{Sr}$, and $\mathrm{Si}$ also have unique advantages in inhibiting osteoclastic activities and facilitating bone formation[12]. The live/dead, CCK-8, rBMSC area and morphology results confirmed that SMSHA facilitated rBMSC attachment, proliferation and spreading to a greater extent than the SHA, SMHA and SSHA scaffolds, suggesting that $\mathrm{Mg}^{2+}$ and $\mathrm{Sr}^{2+}$ have synergistic osteogenic effects[54]. The larger the surface area of the BMSCs is, the greater the possibility of osteogenesis. Additionally, the smaller the area of cell spreading organization is, the greater the tendency of BMSCs to undergo apoptosis[38]. $\mathrm{Mg}^{2+}$ has a significant role in promoting the osteogenic activity of rBMSCs[39]. Therefore, Mg-doped scaffolds showed great potential for osteogenic differentiation of rBMSCs and bone repair. 
Bone-related genes are important factors that regulate bone regeneration. Compared with SHA, the expression of COL1, BMP2, ALP, VEGF and Runx2 increased to varying degrees in rBMSCs cultured on the SMHA, SSHA, and SMSHA scaffolds while GAPDH was constantly expressed, indicating that $\mathrm{Mg}^{2+}$ and $\mathrm{Sr}^{2+}$ can promote the expression of these factors and rBMSC osteogenic differentiation. This gene expression may be stimulated by $\mathrm{Mg}^{2+}, \mathrm{Sr}^{2+}$, or the combination of $\mathrm{Mg}^{2+}$ and $\mathrm{Sr}^{2+}[8,55-57]$ on the basis of mHAws and silica. In the early stage of new bone formation, COL1 participates in bone mineralization to form osteoids, and in the later stage, COL1 aligns with HA crystals to form mature bone[8, 56, 57]. Both $\mathrm{Mg}^{2+}$ and upregulated BMP2 can promote the osteogenic differentiation of BMSCs[8,58]. VEGF plays an important stimulatory role in all stages of bone development and repair, including endochondral ossification and intramembranous ossification, and in bone, it is mainly derived from osteoblasts[59-61]. Runx2 can guide BMSCs to differentiate into osteoblasts and upregulate osteocalcin and osteopontin[62]. mHAws, silica, magnesium and strontium have broad application prospects in bone regeneration. The use of $\mathrm{Mg}-\mathrm{Sr}$ codoped $\mathrm{mHAw}$ scaffolds for bone repair may be a promising method to avoid the limitations of individual application and can synergistically promote bone formation.

\section{Materials And Methods}

\subsection{Scaffolds fabrication and bone repair mechanism}

Calcium nitrate and diammonium hydrogen phosphate were used as raw materials. Solutions with ratios of $\mathrm{Ca}$ (or $\mathrm{Ca}+\mathrm{Mg}, \mathrm{Ca}+\mathrm{Sr}$, or $\mathrm{Ca}+\mathrm{Mg} / \mathrm{Sr}$ )/ $\mathrm{P}$ of 1.67 were configured, urea was used as the nitrogen source and sorbitol was used as the template agent. The $\mathrm{pH}$ of each solution was adjusted to $2 \sim 3$. The prepared solutions were heated in a water bath to $94^{\circ} \mathrm{C}$ for 20 hours to obtain the $\mathrm{mHAws}$. The obtained mHAws were washed with distilled water $6 \sim 7$ times, filtered with suction and dried at $60^{\circ} \mathrm{C}$. Konjac glucomannan was then added to the hydroxyapatite whiskers at a ratio of $10 \%$, and an appropriate amount of ultrapure water was added and the solution was mixed well.

The mixed slurry was extruded through a die to form a porous ceramic scaffold, which was freeze-dried to remove the excess water from the scaffold. The dried scaffold was cut to the required size and placed in a muffle furnace for firing at $450^{\circ} \mathrm{C}$. The fired scaffold was immersed in liquid silica gel, removed after two hours and dried, and the dried scaffold was placed in a muffle furnace again and fired for an additional four hours to prepare a porous ceramic scaffold containing $\mathrm{SiO}_{2}$. In this way, the silicacomplexed mHAw scaffold (SHA), silica-complexed Mg-doped mHAw scaffold (SMHA), silica-complexed Sr-doped mHAw scaffold (SSHA) and silica-complexed Mg-Sr codoped mHAw scaffold (SMSHA) were prepared, and the fabrication process is shown in Figure 7. And the mechanism of SMSHA inducing bone repair in bone defect (Figure 7E-F).

\subsection{Hydrophilicity tests}


Orthopedic grafts need to have a certain degree of hydrophilicity. Testing the hydrophilicity is an indirect method to detect the potential biological application value of these materials. The hydrophilicity of each of the scaffolds was confirmed by measuring the water contact angle (WCA) of the scaffold surface using a water contact angle measurement instrument (CA100A, Shanghai, China). Briefly, $5 \mu$ l of ultrapure water was dropped onto the surface of the holder under ambient conditions, and then the contact angle was measured. All measurements were repeated 3 times on different parts of each scaffold.

\subsection{Pore size tests}

A main characteristic of porous ceramic scaffolds for bone regeneration is their pores, which can perform specific functions. Five samples of each scaffold were randomly selected, and the pore size from the cross-sectional surface of each sample was randomly measured by scanning electron microscopy (SEM; TESCAN VEGA3, Czech Republic, Europe). Then, the average pore size in each of the corresponding scaffolds was calculated.

\subsection{Mechanical properties}

The SHA, SMHA, SSHA and SMSHA scaffolds were cut into $8 \times 8 \times 8 \mathrm{~mm}^{3}$ cubes, and then the mechanical properties of each scaffold was measured using a static and dynamic material testing machine (HY0230, Shanghai, China) with a load of $240 \mathrm{~N}$. Five samples in each group were tested at a speed of 1 $\mathrm{mm} / \mathrm{min}$, and load-displacement curves were obtained. According to ISO 844:2004, the loaddisplacement curves can be used to calculate the Young's moduli and compressive strengths of the scaffolds.

\subsection{Morphology and structural characterization analysis}

It is very important that the surface roughness and morphology of the mHAw scaffolds mimic the porous structure of natural bone, and a rough surface morphology is conducive for the attachment, sprawling, proliferation, and osteogenic differentiation of BMSCs[48]. The mHAw scaffold surface morphology was verified by SEM, and a $10 \mathrm{kV}$ FESEM (S-4800, HITACHI, Tokyo, Japan) equipped with energy dispersive spectroscopy (EDS) capabilities was used to scan the chemical morphology map and various elemental contents of the cross-sections of each scaffold.

\subsection{In vitro cell experiments}

\subsubsection{Cell culture}


Sprague-Dawley (SD) rats (120 g, 5-6 weeks old, purchased from the Department of Veterinary Medicine, Kunming Medical University) were euthanized and disinfected. Their femurs and tibias were removed from both sides, the epiphyses were cut at both ends, and the bone marrow cavities were flushed repeatedly with Dulbecco's modified Eagle's medium (DMEM; Gibco, USA). After centrifugation at 1000 rpm for 5 minutes, the cells were resuspended in DMEM supplemented with $1 \%$ penicillin/streptomycin and $10 \%$ fetal bovine serum (FBS; Gibco, USA) for cell culture. The cells were cultured in an incubator containing $5 \%$ carbon dioxide at $37^{\circ} \mathrm{C}$. Rat bone marrow-derived mesenchymal stem cells (rBMSCs) were obtained after 7 days of culture (the nonadherent cells were removed during the culture and the cells were passaged when the fusion exceeded $80 \%$ ) and passages 3 to 5 were used for cell experiments.

\subsubsection{Cell viability and proliferation}

After the rBMSCs $\left(1 \times 10^{5}\right)$ were incubated on each scaffold $(8 \mathrm{~mm} \times 2 \mathrm{~mm})$ for 3 days, the survival of the rBMSCs was determined by fluorescent staining; that is, rBMSCs were treated with a staining kit (Solarbio, China) containing calcein-AM and EthD-1 for the live/dead staining assay. In this assay, dead cells were stained red, and living cells were stained green. To further evaluate the proliferation of rBMSCs cultured for 1 day, 3 days and 7 days according to the aforementioned method, a sample of complete DMEM was removed at each time point, and $550 \mu$ of DMEM containing $10 \%$ Cell Counting Kit-8 (CCK-8, Dojindo, Japan) solution was added to each microplate well. After incubation for 1-4 hours under cell culture conditions, 5 replicate wells were set in a 96-well plate, and $100 \mu \mathrm{l}$ of incubation solution was added to each well. The absorbance of each solution was measured with a microplate reader (Bio-Rad 680, USA) at a wavelength of $450 \mathrm{~nm}$ to evaluate the viability and proliferation ability of the rBMSCs on each scaffold.

\subsubsection{Cell morphology and surface area}

To analyze the effects of various scaffolds on cell morphology and surface area, rBMSCs cocultured with the four scaffolds were washed twice with PBS after coculture for 3 days. The cytoplasm of the rBMSCs was stained with calcein-AM obtained from the live/dead viability kit and used to stain live cells. Fluorescence images were obtained with an upright fluorescence microscope (OLYMPUS, BX53F, Tokyo, Japan), the morphological shapes of the rBMSCs were observed, and then the typical cell surface areas were calculated using cellSens Standard software (OLYMPUS, Tokyo, Japan).

\subsubsection{Osteogenic gene expression analysis}

The effects of the scaffolds on the expression levels of rBMSC osteogenic genes was studied by real-time quantitative polymerase chain reaction (RT-qPCR). rBMSCs were seeded on each scaffold in duplicate at a density of $2 \times 10^{5}$ cells per scaffold. After 7 days or 14 days of culture, the cells on the scaffold were lysed with $1 \mathrm{ml}$ of TRIzol (Invitrogen, USA) to isolate and obtain total RNA. Complementary DNA (cDNA) 
was synthesized using the PrimeScript First Strand cDNA Synthesis kit (Thermo Scientific, Lithuania) according to the manufacturer's instructions. A real-time PCR kit (FastStart Universal SYBR@ Green Master, Roche, Germany) was used on a cycler (Applied Biosystem, Australia) to analyze type I collagen (COL1), bone morphogenetic protein 2 (BMP2), Runt-related transcription factor 2 (Runx2), alkaline phosphatase (ALP), and vascular endothelial growth factor (VEGF) CDNA. The housekeeping gene glyceraldehyde 3-phosphate dehydrogenase (GAPDH) was used to analyze the changes in the expression of the above genes.

\subsection{Statistical analysis}

To determine the differences between each scaffold at each time point, one-way analysis of variance (ANOVA) and the Student-Newman-Keuls post hoc test were used for statistical analysis. Quantitative data are expressed as the mean \pm standard deviation. A value of $P<0.05$ was considered statistically significant. GraphPad Prism 7 software was used for all statistical analyses.

\section{Conclusion}

Based on the strategy of low-temperature sintering and extrusion molding, we synthesized four scaffolds: SHA, SMHA, SSHA and SMSHA, which are mainly composed of micro-hydroxyapatite whiskers doped with magnesium and strontium and complexed with silica to enhance the mechanical properties. Each scaffold has a high specific porous surface area and porosity, and their rough surface morphology can promote SD rBMSC adhesion and proliferation. Compared with SHA, the SMHA, SSHA and SMSHA scaffolds more effectively stimulated the osteogenic and angiogenic differentiation of rBMSCs in vitro. Therefore, the prepared scaffolds have strong potential application value in the field of biomedical bone tissue engineering. In further research, we will graft these four scaffolds in animals to verify their capacity to promote bone regeneration and new blood vessel formation in vivo.

\section{Abbreviations}

BTE

bone tissue engineering; mHAws:micron-sized HA whiskers; SHA:silica-complexed mHAw scaffold; SMHA:silica-complexed Mg-doped mHAw scaffold; SSHA:silica-complexed Sr-doped mHAw scaffold; SMSHA:silica-complexed Mg-Sr codoped mHAw scaffold; WCA:water contact angle; SEM:scanning electron microscopy; EDS:energy dispersive spectroscopy; DMEM:Dulbecco's modified Eagle's medium; FBS:fetal bovine serum; rBMSCs:rat bone marrow-derived mesenchymal stem cells; BMSCs:bone marrow mesenchymal stem cells; CCK-8:RT-qPCR:real-time quantitative polymerase chain reaction; Cell Counting Kit-8; COL 1:type I collagen; BMP2:bone morphogenetic protein 2; Runx2:Runt-related transcription factor 2; ALP:alkaline phosphatase; VEGF:vascular endothelial growth factor; GAPDH:glyceraldehyde 3phosphate dehydrogenase. 


\section{Declarations}

\section{Ethics approval and consent to participate}

The experimental protocol was approved by the Animal Experiment Ethics Committee of Kunming Medical University (kmmu2021268).

\section{Consent for publication}

Not applicable

\section{Competing interests}

The authors declare that they have no competing interests.

\section{Founding}

The present study was funded by the National Natural Science Foundation of China (grant No.82060416,81760029), the Health Science and Technology Project of Yunnan province (grant No.2017NS022), Special program for Applied basic research of Yunnan Science and Technology AgencyKunming Medical University (grant No.2018FE001- 146, 2018FE001-213, 2019FE001-240, 2019FE001079), Yunnan Province Clinical Center for Bone and joint Diseases (ZX2019-03-04), Scientific and technological innovation team for spine degenerative disease research of Kunming Medical University (grant No. CXTD201805), and Yunnan health training project of high level talents.

\section{Authors' contributions}

Chengyong Li and Bing Wang conceived the idea; Chengyong Li, Tingting Yan and Zhenkai Lou designed the experiment, Chengyong Li, Zhimin Jiang and Zhi Shi carried out the experiments; Chengyong Li, Tingting Yan, Zhenkai Lou and Bing Wang analyzed the data and wrote the manuscript; Qinghua Chen and Zhiqiang Gong assisted with the experiments; Bing Wang, Qinghua Chen and Zhiqiang Gong contributed to scientific discussion of the paper.

\section{Acknowledgements}

Not applicable

\section{Availability of data and materials}

The datasets used and/or analysed during the current study are available from the corresponding author on reasonable request.

\section{Authors' information}


1 Department of Orthopedics, First Affiliated Hospital of Kunming Medical University, Kunming Medical University, Kunming 650032, China; 2 Faculty of Materials Science and Engineering, Kunming University of Science and Technology, Kunming 650093, China;

\section{References}

1. Einhorn TA, Gerstenfeld LC. Fracture healing: mechanisms and interventions. Nat Rev Rheumatol. 2014;11(1):45-54.

2. Shen X, Zhang Y, Gu Y, Xu Y, Liu Y, Li B, Chen L. Sequential and sustained release of SDF-1 and BMP2 from silk fibroin-nanohydroxyapatite scaffold for the enhancement of bone regeneration. Biomaterials. 2016;106:205-16.

3. Tarchala M, Harvey EJ, Barralet J. Biomaterial-Stabilized Soft Tissue Healing for Healing of CriticalSized Bone Defects: the Masquelet Technique. Adv Healthc Mater. 2016;5(6):630-40.

4. Liu WC, Chen S, Zheng L, Qin L. Angiogenesis Assays for the Evaluation of Angiogenic Properties of Orthopaedic Biomaterials - A General Review. Adv Healthc Mater 2017, 6(5).

5. Wang SJ, Jiang D, Zhang ZZ, Chen YR, Yang ZD, Zhang JY, Shi J, Wang X, Yu JK. Biomimetic Nanosilica-Collagen Scaffolds for In Situ Bone Regeneration: Toward a Cell-Free, One-Step Surgery. Adv Mater. 2019;31(49):e1904341.

6. Koons GL, Diba M, Mikos AG. Materials design for bone-tissue engineering. Nature Reviews Materials. 2020;5(8):584-603.

7. Liu H, Xu GW, Wang YF, Zhao HS, Xiong S, Wu Y, Heng BC, An CR, Zhu GH, Xie DH. Composite scaffolds of nano-hydroxyapatite and silk fibroin enhance mesenchymal stem cell-based bone regeneration via the interleukin 1 alpha autocrine/paracrine signaling loop. Biomaterials. 2015;49:103-12.

8. Lai Y, Li Y, Cao H, Long J, Wang X, Li L, Li C, Jia Q, Teng B, Tang T, et al. Osteogenic magnesium incorporated into PLGA/TCP porous scaffold by 3D printing for repairing challenging bone defect. Biomaterials. 2019;197:207-19.

9. Sun TW, Yu WL, Zhu YJ, Yang RL, Shen YQ, Chen DY, He YH, Chen F. Hydroxyapatite Nanowire@Magnesium Silicate Core-Shell Hierarchical Nanocomposite: Synthesis and Application in Bone Regeneration. ACS Appl Mater Interfaces. 2017;9(19):16435-47.

10. Nabiyouni M, Brückner T, Zhou H, Gbureck U, Bhaduri SB. Magnesium-based bioceramics in orthopedic applications. Acta Biomater. 2018;66:23-43.

11. Shuai C, Li S, Peng S, Feng P, Lai Y, Gao C. Biodegradable metallic bone implants. Materials Chemistry Frontiers. 2019;3(4):544-62.

12. Wu C, Chen Z, Yi D, Chang J, Xiao Y. Multidirectional effects of Sr-, Mg-, and Si-containing bioceramic coatings with high bonding strength on inflammation, osteoclastogenesis, and osteogenesis. ACS Appl Mater Interfaces. 2014;6(6):4264-76. 
13. Saidak Z, Marie PJ. Strontium signaling: molecular mechanisms and therapeutic implications in osteoporosis. Pharmacol Ther. 2012;136(2):216-26.

14. Cox SC, Thornby JA, Gibbons GJ, Williams MA, Mallick KK. 3D printing of porous hydroxyapatite scaffolds intended for use in bone tissue engineering applications. Mater Sci Eng C Mater Biol Appl. 2015;47:237-47.

15. Li X, Ma B, Li J, Shang L, Liu H, Ge S. A method to visually observe the degradation-diffusionreconstruction behavior of hydroxyapatite in the bone repair process. Acta Biomater. 2020;101:55464.

16. Saleem M, Rasheed S, Yougen C. Silk fibroin/hydroxyapatite scaffold: a highly compatible material for bone regeneration. Sci Technol Adv Mater. 2020;21(1):242-66.

17. Xie L, Yu H, Yang W, Zhu Z, Yue L. Preparation, in vitro degradability, cytotoxicity, and in vivo biocompatibility of porous hydroxyapatite whisker-reinforced poly(L-lactide) biocomposite scaffolds. J Biomater Sci Polym Ed. 2016;27(6):505-28.

18. Shuai C, Cao Y, Gao C, Feng P, Xiao T, Peng S. Hydroxyapatite Whisker Reinforced 63s Glass Scaffolds for Bone Tissue Engineering. Biomed Res Int. 2015;2015:1-8.

19. Kane RJ, Weiss-Bilka HE, Meagher MJ, Liu Y, Gargac JA, Niebur GL, Wagner DR, Roeder RK. Hydroxyapatite reinforced collagen scaffolds with improved architecture and mechanical properties. Acta Biomater. 2015;17:16-25.

20. Li Y, Liu G, Zhai Z, Liu L, Li H, Yang K, Tan L, Wan P, Liu X, Ouyang Z, et al. Antibacterial Properties of Magnesium In Vitroand in anIn VivoModel of Implant-Associated Methicillin-Resistant Staphylococcus aureus Infection. Antimicrob Agents Chemother. 2014;58(12):7586-91.

21. Feyerabend F, Wendel HP, Mihailova B, Heidrich S, Agha NA, Bismayer U, Willumeit-Romer R. Blood compatibility of magnesium and its alloys. Acta Biomater. 2015;25:384-94.

22. Yan T, Tan L, Zhang B, Yang K. Fluoride Conversion Coating on Biodegradable AZ31B Magnesium Alloy. Journal of Materials Science Technology. 2014;30(7):666-74.

23. Shadjou N, Hasanzadeh M. Bone tissue engineering using silica-based mesoporous nanobiomaterials:Recent progress. Mater Sci Eng C Mater Biol Appl. 2015;55:401-9.

24. Gotz W, Tobiasch E, Witzleben S, Schulze M. Effects of Silicon Compounds on Biomineralization, Osteogenesis, and Hard Tissue Formation. Pharmaceutics 2019, 11(3).

25. Honda M, Kikushima K, Kawanobe Y, Konishi T, Mizumoto M, Aizawa M. Enhanced early osteogenic differentiation by silicon-substituted hydroxyapatite ceramics fabricated via ultrasonic spray pyrolysis route. J Mater Sci Mater Med. 2012;23(12):2923-32.

26. Niu LN, Jiao K, Qi YP, Nikonov S, Yiu CK, Arola DD, Gong SQ, El-Marakby A, Carrilho MR, Hamrick MW, et al. Intrafibrillar silicification of collagen scaffolds for sustained release of stem cell homing chemokine in hard tissue regeneration. FASEB J. 2012;26(11):4517-29.

27. Liu J, Rawlinson SC, Hill RG, Fortune F. Strontium-substituted bioactive glasses in vitro osteogenic and antibacterial effects. Dent Mater. 2016;32(3):412-22. 
28. Brauer DS, Karpukhina N, Kedia G, Bhat A, Law RV, Radecka I, Hill RG. Bactericidal strontiumreleasing injectable bone cements based on bioactive glasses. J R Soc Interface. 2013;10(78):20120647.

29. Chen Y, Zheng Z, Zhou R, Zhang H, Chen C, Xiong Z, Liu K, Wang X. Developing a StrontiumReleasing Graphene Oxide-/Collagen-Based Organic-Inorganic Nanobiocomposite for Large Bone Defect Regeneration via MAPK Signaling Pathway. ACS Appl Mater Interfaces. 2019;11(17):1598697.

30. Xing $M$, Wang $X$, Wang $E$, Gao L, Chang J. Bone tissue engineering strategy based on the synergistic effects of silicon and strontium ions. Acta Biomater. 2018;72:381-95.

31. Alkhraisat MH, Rueda C, Cabrejos-Azama J, Lucas-Aparicio J, Marino FT, Torres Garcia-Denche J, Jerez LB, Gbureck U, Cabarcos EL. Loading and release of doxycycline hyclate from strontiumsubstituted calcium phosphate cement. Acta Biomater. 2010;6(4):1522-8.

32. Mao L, Xia L, Chang J, Liu J, Jiang L, Wu C, Fang B. The synergistic effects of Sr and Si bioactive ions on osteogenesis, osteoclastogenesis and angiogenesis for osteoporotic bone regeneration. Acta Biomater. 2017;61:217-32.

33. Zhu Q, Li X, Fan Z, Xu Y, Niu H, Li C, Dang Y, Huang Z, Wang Y, Guan J. Biomimetic polyurethane/TiO2 nanocomposite scaffolds capable of promoting biomineralization and mesenchymal stem cell proliferation. Mater Sci Eng C Mater Biol Appl. 2018;85:79-87.

34. Sharifi F, Atyabi SM, Norouzian D, Zandi M, Irani S, Bakhshi H. Polycaprolactone/carboxymethyl chitosan nanofibrous scaffolds for bone tissue engineering application. Int J Biol Macromol. 2018;115:243-8.

35. Wang Q, Feng Y, He M, Zhao W, Qiu L, Zhao C. A Hierarchical Janus Nanofibrous Membrane Combining Direct Osteogenesis and Osteoimmunomodulatory Functions for Advanced Bone Regeneration. Adv Func Mater. 2020;31(8):2008906.

36. Henkel J, Woodruff MA, Epari DR, Steck R, Glatt V, Dickinson IC, Choong PF, Schuetz MA, Hutmacher DW. Bone Regeneration Based on Tissue Engineering Conceptions - A 21st Century Perspective. Bone Res. 2013;1(3):216-48.

37. Zhang C, Wang W, Hao X, Peng Y, Zheng Y, Liu J, Kang Y, Zhao F, Luo Z, Guo J, et al. A Novel Approach to Enhance Bone Regeneration by Controlling the Polarity of GaN/AIGaN Heterostructures. Adv Func Mater. 2020;31(5):2007487.

38. Jiao F, Zhao Y, Sun Q, Huo B. Spreading area and shape regulate the apoptosis and osteogenesis of mesenchymal stem cells on circular and branched micropatterned islands. J Biomed Mater Res A. 2020;108(10):2080-9.

39. Xiang H, Yang Q, Gao Y, Zhu D, Pan S, Xu T, Chen Y. Cocrystal Strategy toward Multifunctional 3DPrinting Scaffolds Enables NIR-Activated Photonic Osteosarcoma Hyperthermia and Enhanced Bone Defect Regeneration. Adv Func Mater. 2020;30(25):1909938.

40. Schoenenberger AD, Tempfer H, Lehner C, Egloff J, Mauracher M, Bird A, Widmer J, Maniura-Weber K, Fucentese SF, Traweger A, et al. Macromechanics and polycaprolactone fiber organization drive 
macrophage polarization and regulate inflammatory activation of tendon in vitro and in vivo. Biomaterials. 2020;249:120034.

41. Lv L, Xie Y, Li K, Hu T, Lu X, Cao Y, Zheng X. Unveiling the Mechanism of Surface HydrophilicityModulated Macrophage Polarization. Advanced Healthcare Materials. 2018;7(19):1800675.

42. Zhang X, Zu H, Zhao D, Yang K, Tian S, Yu X, Lu F, Liu B, Yu X, Wang B, et al. lon channel functional protein kinase TRPM7 regulates Mg ions to promote the osteoinduction of human osteoblast via PI3K pathway: In vitro simulation of the bone-repairing effect of Mg-based alloy implant. Acta Biomater. 2017;63:369-82.

43. Su NY, Peng TC, Tsai PS, Huang CJ. Phosphoinositide 3-kinase/Akt pathway is involved in mediating the anti-inflammation effects of magnesium sulfate. J Surg Res. 2013;185(2):726-32.

44. Liu Y, Luo D, Wang T. Hierarchical Structures of Bone and Bioinspired Bone Tissue Engineering. Small. 2016;12(34):4611-32.

45. Diana L. Lopes CM-C, Mariana B. Oliveira, João F. Mano: <Bone Physiology as Inspiration for Tissue Regenerative Therapies.pdf>. biomaterials 2018, 185.

46. Kim HD, Amirthalingam S, Kim SL, Lee SS, Rangasamy J, Hwang NS. Biomimetic Materials and Fabrication Approaches for Bone Tissue Engineering. Advanced Healthcare Materials. 2017;6(23):1700612.

47. Zhang X, Zeng D, Li N, Wen J, Jiang X, Liu C, Li Y. Functionalized mesoporous bioactive glass scaffolds for enhanced bone tissue regeneration. Scientific Reports 2016, 6(1).

48. Du Y, Guo JL, Wang J, Mikos AG, Zhang S. Hierarchically designed bone scaffolds: From internal cues to external stimuli. Biomaterials. 2019;218:119334.

49. Peng Z, Zhao T, Zhou Y, Li S, Li J, Leblanc RM. Bone Tissue Engineering via Carbon-Based Nanomaterials. Adv Healthc Mater. 2020;9(5):e1901495.

50. Hengsberger S. AKPZ: A Combined atomic force microscopy and nanoindentation technique to investigate the elastic properties of bone structural units.pdf>. European Cells Materials. 2001;1:127.

51. Jae-Young Rho TYT, George M. Pharr. Elastic properties of microstucral components of human bone tissue as measured by nanoindentation.pdf $>$. biomaterials 1997, 18:1325-1330.

52. Baba Ismail YM, Wimpenny I, Bretcanu O, Dalgarno K, El Haj AJ. Development of multisubstituted hydroxyapatite nanopowders as biomedical materials for bone tissue engineering applications. $J$ Biomed Mater Res A. 2017;105(6):1775-85.

53. Landi E, Uggeri J, Sprio S, Tampieri A, Guizzardi S. Human osteoblast behavior on as-synthesized SiO(4) and B-CO(3) co-substituted apatite. J Biomed Mater Res A. 2010;94(1):59-70.

54. Wang S, Liu L, Zhou X, Yang D, Shi Z, Hao Y. Effect of strontium-containing on the properties of Mgdoped wollastonite bioceramic scaffolds. Biomed Eng Online. 2019;18(1):119.

55. Wu C, Chen Z, Yi D, Chang J, Xiao Y. Multidirectional Effects of Sr-, Mg-, and Si-Containing Bioceramic Coatings with High Bonding Strength on Inflammation, Osteoclastogenesis, and Osteogenesis. ACS 
Appl Mater Interfaces. 2014;6(6):4264-76.

56. Jee-Wook Lee H-SH, Han K-J, Park J, Jeon H, Ok M-R, Seok H-K, Ahn J-P, Lee KE, Lee D-H, Yang S-J, Sung-Youn Cho,Pil-Ryung Cha, Hoon Kwon, Tae-Hyun Nam, Jee Hye Lo Han, Rho H-J, Lee K-S, YuChan Kim,and Diego Mantovani: Long-term clinical study and multiscale analysis of in vivo biodegradation mechanism of $\mathrm{Mg}$ alloy. Proceedings of the National Academy of Sciences of the United States of America 2016, 113:716-721.

57. Yoshizawa S, Brown A, Barchowsky A, Sfeir C. Magnesium ion stimulation of bone marrow stromal cells enhances osteogenic activity, simulating the effect of magnesium alloy degradation. Acta Biomater. 2014;10(6):2834-42.

58. Díaz-Tocados JM, Herencia C, Martínez-Moreno JM, Montes de Oca A, Rodríguez-Ortiz ME, Vergara N, Blanco A, Steppan S, Almadén Y, Rodríguez M. Muñoz-Castañeda JR: Magnesium Chloride promotes Osteogenesis through Notch signaling activation and expansion of Mesenchymal Stem Cells. Scientific Reports 2017, 7(1).

59. Street J, Bao M, deGuzman L, Bunting S, Peale FV Jr, Ferrara N, Steinmetz H, Hoeffel J, Cleland JL, Daugherty $A$, et al. Vascular endothelial growth factor stimulates bone repair by promoting angiogenesis and bone turnover. Proc Natl Acad Sci U S A. 2002;99(15):9656-61.

60. Keramaris NC, Calori GM, Nikolaou VS, Schemitsch EH, Giannoudis PV. Fracture vascularity and bone healing: A systematic review of the role of VEGF. Injury. 2008;39:45-57.

61. DECKERS MK MARTINEML, CHRIS VAN DER BENT, TAKEYOSHI YAMASHITA, PAPAPOULOS SOCRATESE. CLEMENS W. G. M. LO" WIK: Expression of vascular endothelial growth factors and their receptors during osteoblast differentiation.pdf>. Endocrinology. 2000;141:1667-74.

62. García JR, García AJ. Biomaterial-mediated strategies targeting vascularization for bone repair. Drug Delivery Translational Research. 2015;6(2):77-95.

\section{Figures}




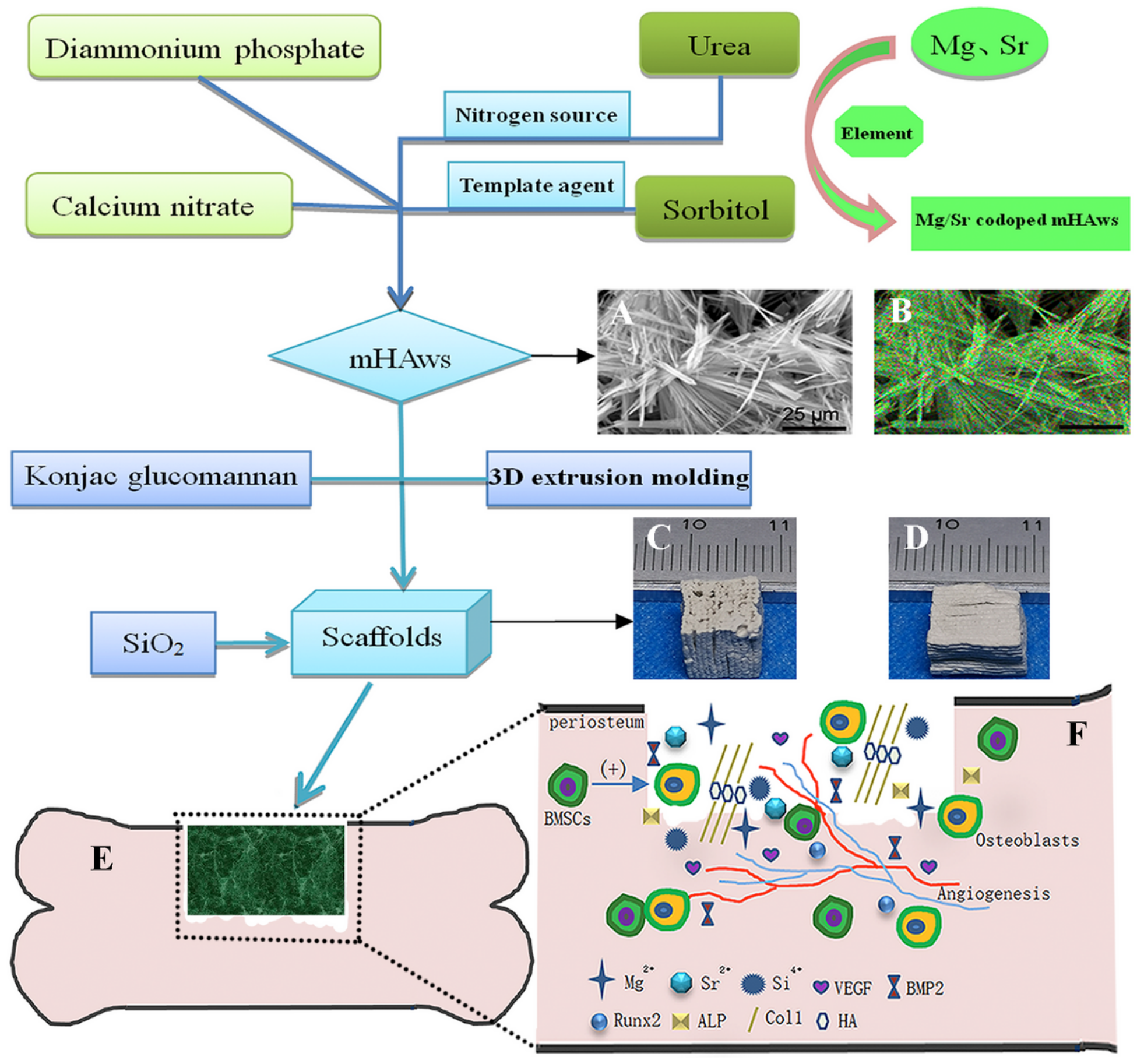

Figure 1

Morphologies of the micro-hydroxyapatite whiskers observed by SEM (A). Hydrophilic images of SHA, SMHA, SSHA and SMSHA (B-E), respectively. Water contact angles of SHA, SMHA, SSHA and SMSHA (F). Pore sizes of the four scaffolds $(G)$. Young's moduli of the four scaffolds $(H)$. The compressive strengths of four scaffolds (I). ( $n=5, * P<0.05, \# P>0.05$ compared with SHA). 


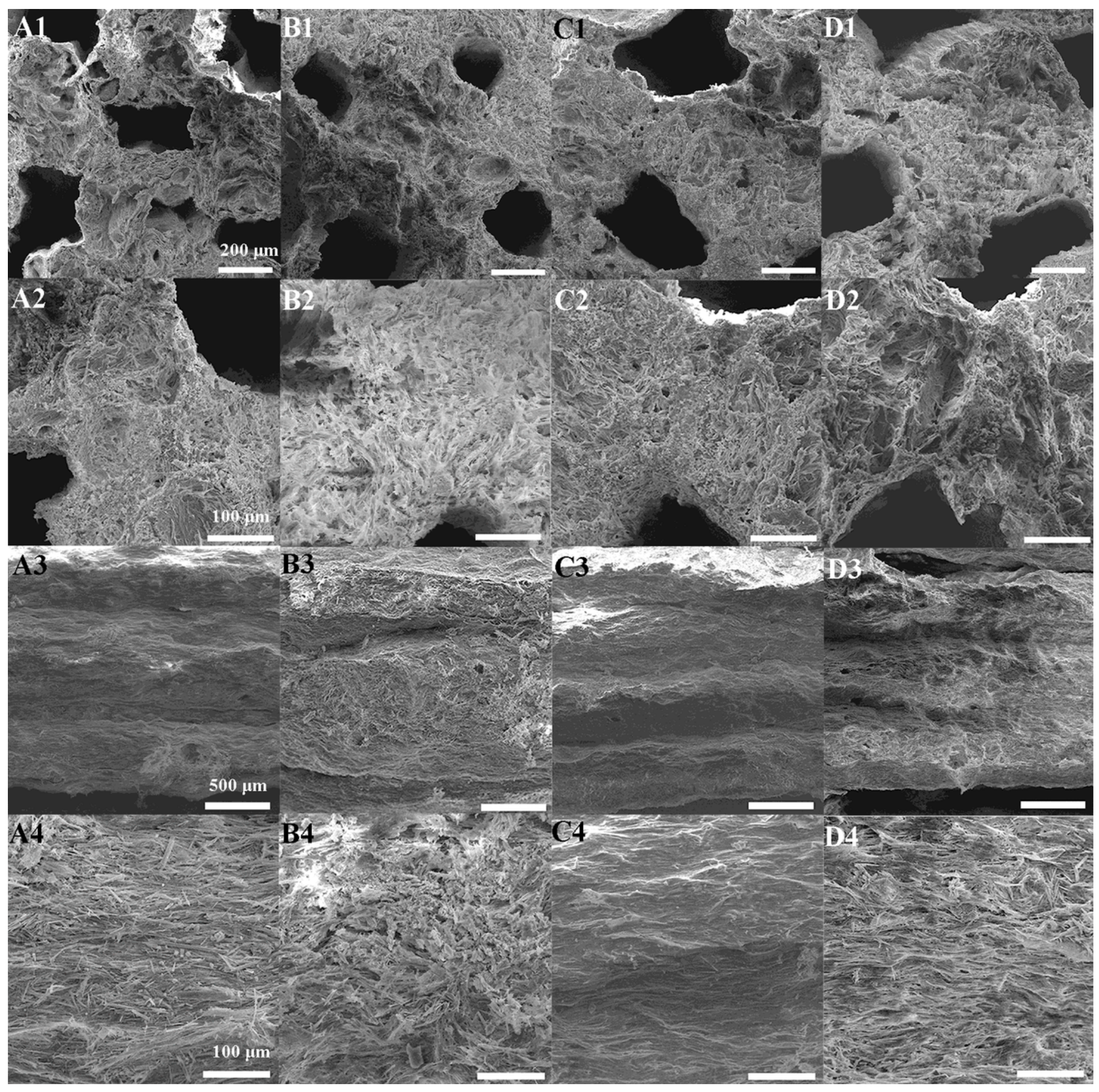

Figure 2

Surface morphology and porous structure analyses. The macroporous surfaces of SHA (A1-A2), SMHA (B1-B2), SSHA (C1-C2) and SMSHA (D1-D2). The microporous surfaces of SHA (A3-A4), SMHA (B3-B4), SSHA (C3-C4) and SMSHA (D3-D4). 


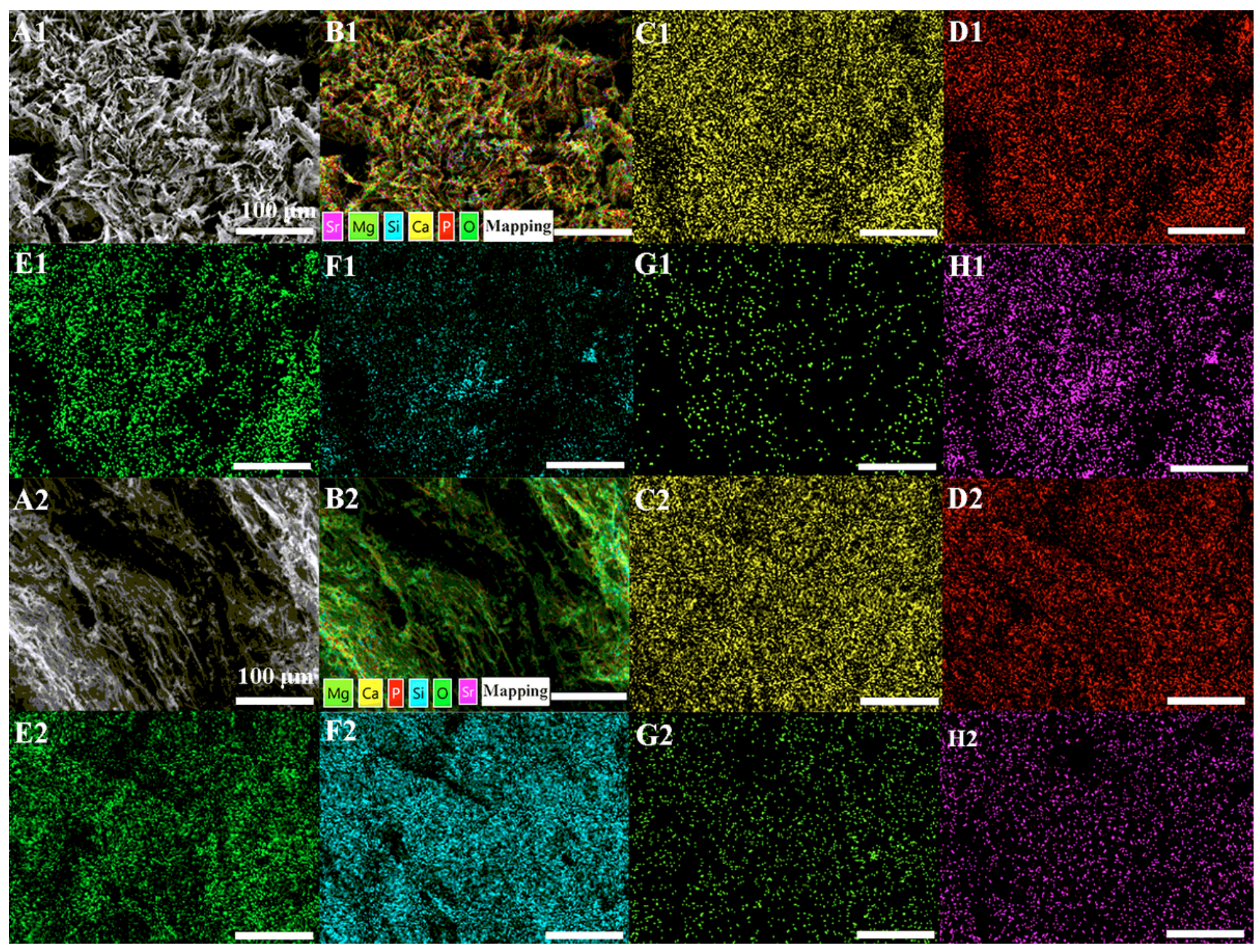

Figure 3

Elemental mapping images of SMSHA. SEM images (A1, A2). All elemental distribution images (B1, B2). $\mathrm{Ca}, \mathrm{P}, \mathrm{O}, \mathrm{Si}, \mathrm{Mg}$, Sr distribution images $(\mathrm{C} 1-\mathrm{H} 1, \mathrm{C} 2-\mathrm{H} 2)$, respectively. Macroporous surface $(\mathrm{A} 1-\mathrm{H} 1)$ and microporous surface $(\mathrm{A} 2-\mathrm{H} 2)$, respectively. 

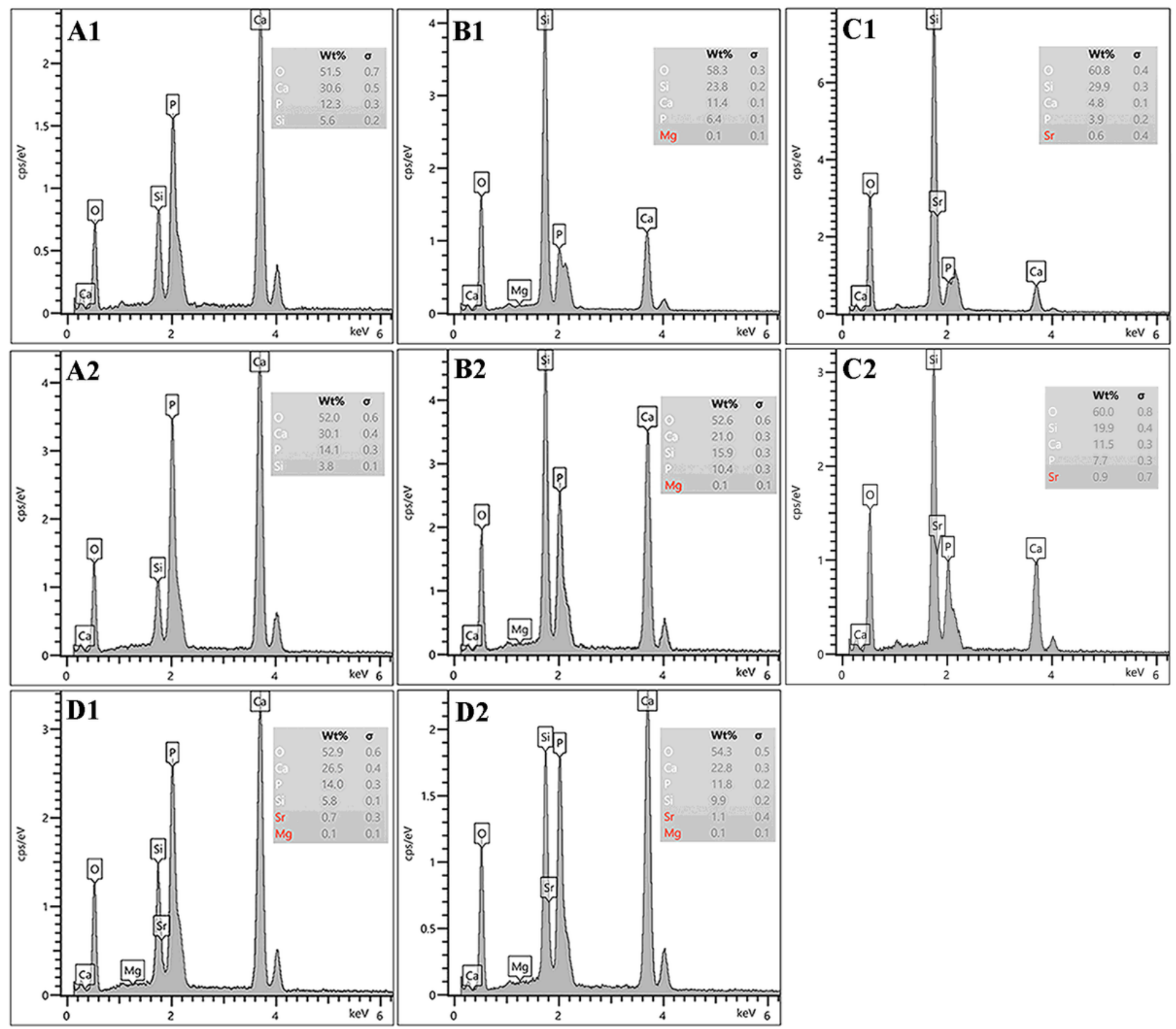

\section{Figure 4}

Microporous surface EDS patterns of the prepared SHA, SMHA, SSHA and SMSHA scaffolds (A1-D1), respectively. Microporous surface EDS patterns of the prepared SHA, SMHA, SSHA and SMSHA scaffolds (A2-D2), respectively. 


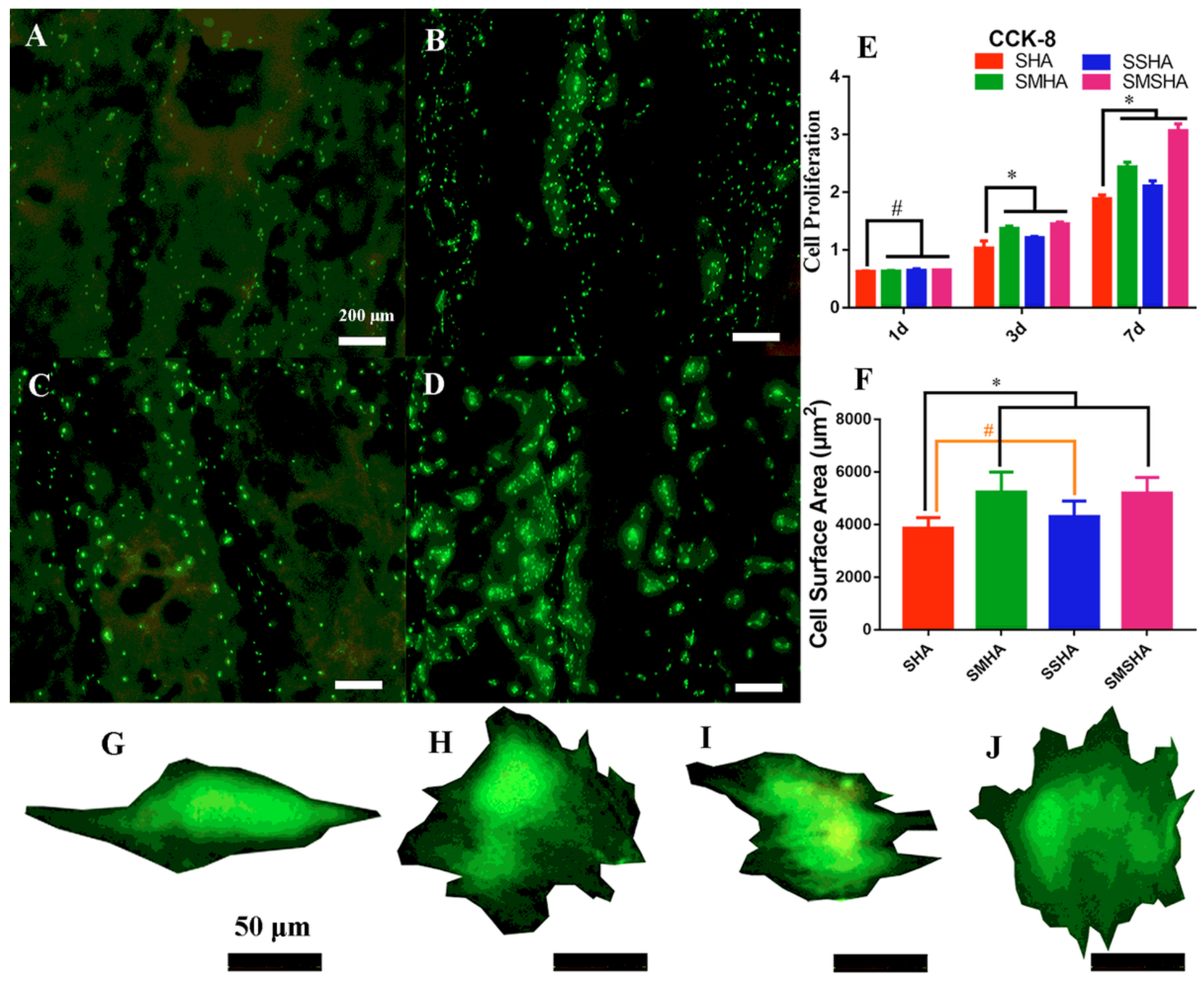

Figure 5

Live/dead staining assessed the viability of rBMSCs cultured on the SHA, SMHA, SSHA and SMSHA scaffolds (A-D), respectively. The CCK-8 assay assessed the proliferation of rBMSCs $(E)(n=5, * P<0.05$, \# $P>0.05$ compared with SHA). The surface area (F) and typical cell morphology (G-J) of rBMSCs cocultured with SHA, SMHA, SSHA and SMSHA for 3 days, respectively $(n=5, * P<0.05, \# P>0.05$ compared with SHA). 


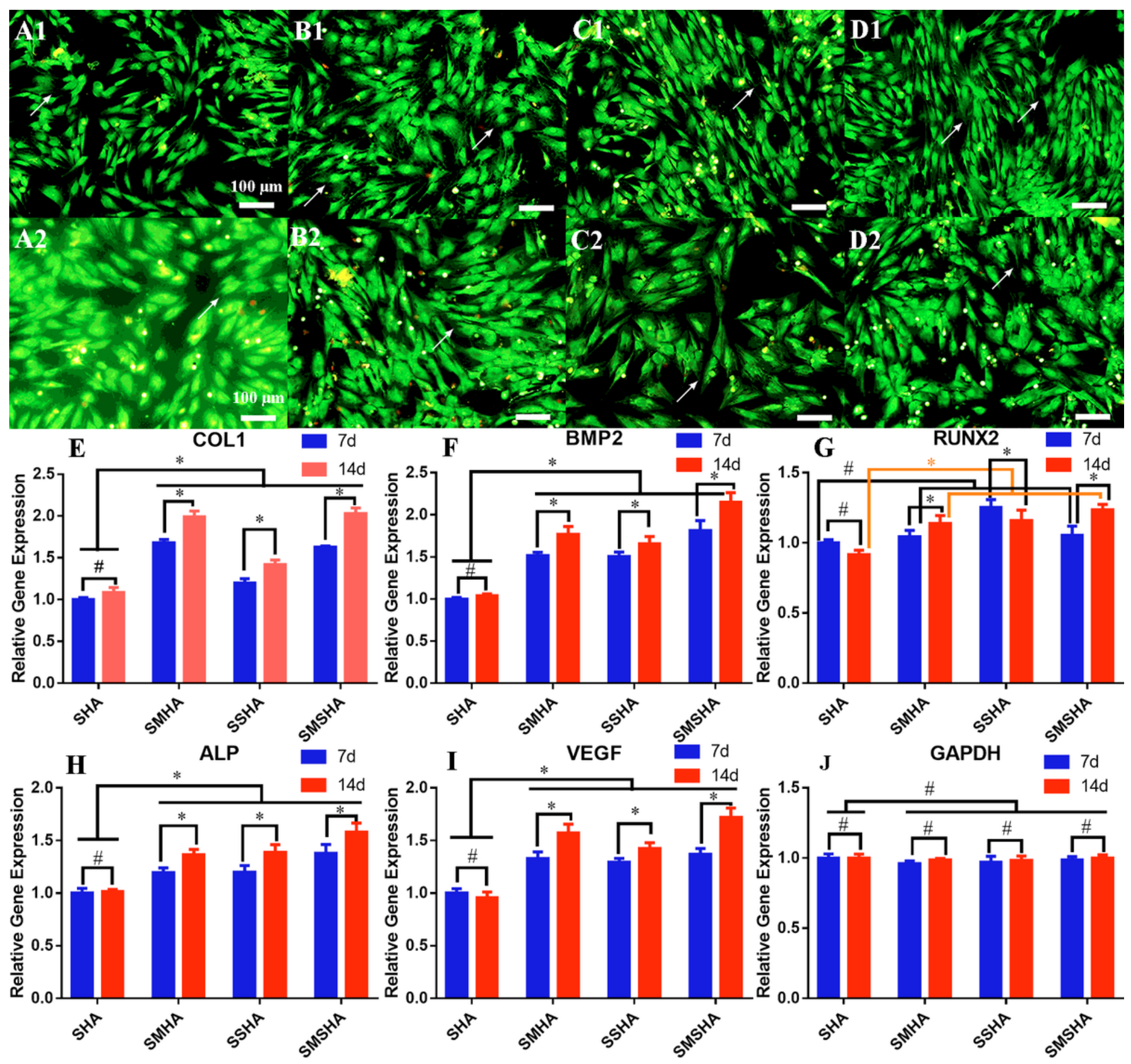

Figure 6

Morphology of the rBMSCs cocultured with the four scaffolds and fold changes in osteogenic-related gene expression in rBMSCs cultured on the four scaffolds. Morphologies of the rBMSCs cocultured with SHA, SMHA, SSHA and SMSHA for 3 days (A1-D1) and 7 days (A2-D2) (10x), respectively; arrows indicate the filopodia. The changes in expression of COL1, BMP2, Runx2, ALP and VEGF in rBMSCs cultured on the four scaffolds (E-J) compared with GAPDH (N) $(n=3, * P<0.05$, \# P $>0.05$ compared with SHA or 14 d compared with $7 \mathrm{~d}$ of each scaffold). 


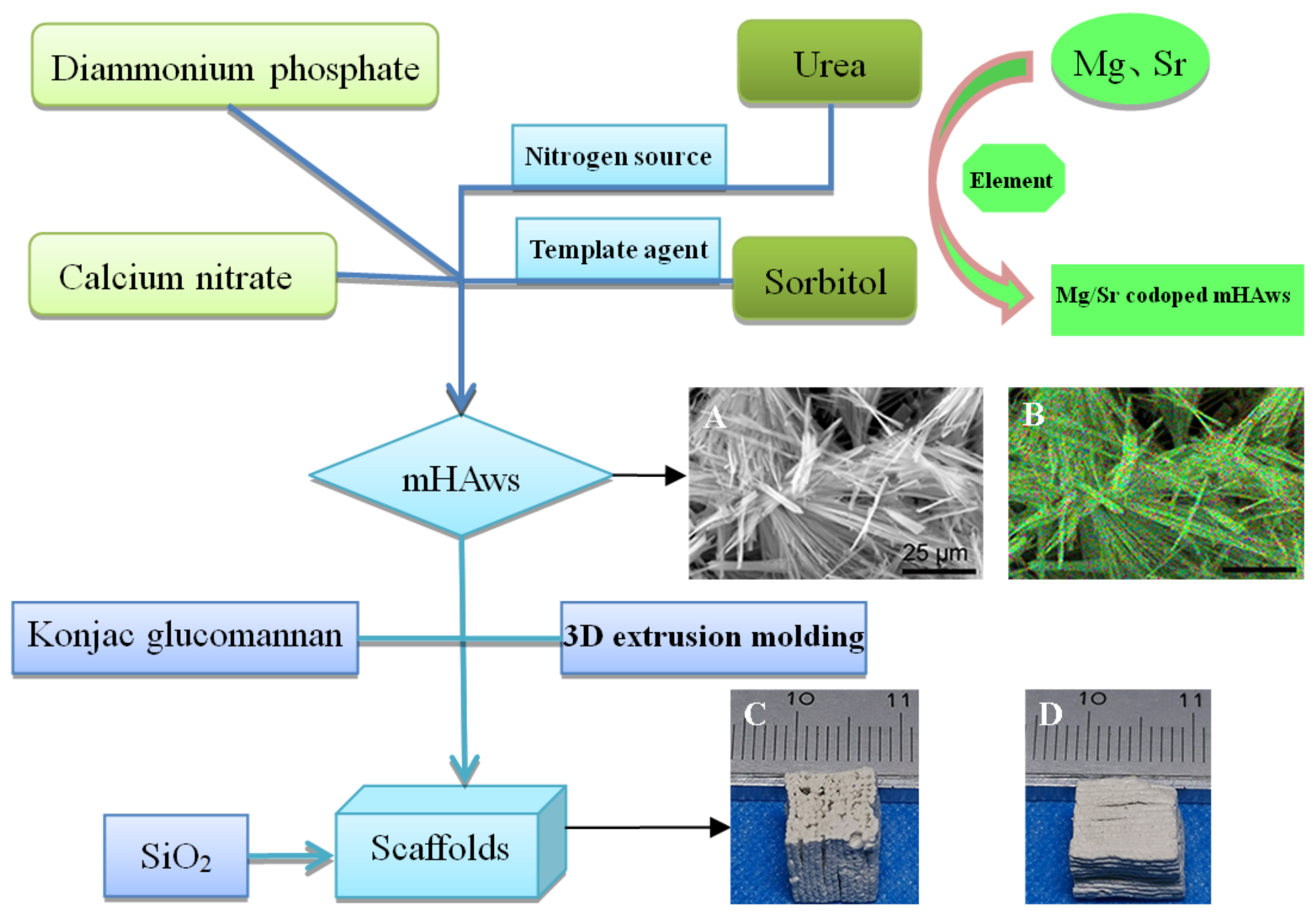

Figure 7

Fabrication of a porous hierarchical scaffold with Mg-Sr codoped SiO2 complexed micro-hydroxyapatite whiskers (mHAws). SEM micrograph of Mg-Sr codoped mHAws (A). Element mapping of Mg-Sr codoped mHAws (B). Prepared SMSHA scaffold (size $0.8 \times 0.8 \times 0.8 \mathrm{~cm}$ ): the macroporous surface (C) and the microporous surface (D). Schematic diagram of scaffold filling bone defect (E) for BMSCs osteogenic differentiation and bone regeneration $(F)$.

\section{Supplementary Files}

This is a list of supplementary files associated with this preprint. Click to download.

- FigureS1.tif

- SupportingInformation.doc

- Figures2.tif

- FigureS3.tif 